\title{
SERVICE LEVEL AS PERFORMANCE INDICATOR FOR MULTIPLE PART FAMILIES IN A RECONFIGURABLE MANUFACTURING SYSTEM
}

\author{
Faisal Hasan ${ }^{1 *}$, P.K. Jain ${ }^{2}$ and Dinesh Kumar ${ }^{2}$ \\ ${ }^{1}$ Department of Mechanical and Industrial Engineering \\ Indian Institute of Technology Roorkee, Roorkee-247667, Uttrakhand, India. \\ *Email: faisalhasan123@gmail.com \\ Phone: +91-9368682702 \\ ${ }^{2}$ Department of Mechanical and Industrial Engineering \\ Indian Institute of Technology Roorkee \\ Roorkee-247667, Uttrakhand, India.
}

\begin{abstract}
Reconfigurable manufacturing systems are recognized as next generation manufacturing systems capable of providing the exact functionality and capacity as and when required. The reconfiguration of the system depends upon the ease with which any machine can be added, removed or re-adjusted for upcoming configuration from any initial or outgoing configuration. The efforts required while changing any existing configuration to a new configuration have serious implications on the cost aspect as well. The complexity and economics involved in changing one configuration to another depend on the existing initial configuration and the new upcoming configuration required for subsequent production of part families. In the present paper, based on the different types of effort associated with the reconfiguration process, a new indicator of performance termed as "Service Level" is proposed. The proposed indicator is modeled for a multipart reconfigurable manufacturing system. The proposed methodology is demonstrated using a numerical example. The values obtained for service levels while switching from one configuration to another were calculated for a serial product flow line. Some of the important implications regarding service level evaluation and implementation are finally discussed.
\end{abstract}

Keywords: reconfigurable manufacturing system; part families; service level; performance.

\section{INTRODUCTION}

The present manufacturing scenario is characterized by several market variables like unpredictable demand, short product life-cycles, customized products, and rapid changes in the process technology. These market variables have forced the manufacturing systems to adapt to the changing requirements efficiently and effectively. Also, in this global manufacturing era, one of the important challenges faced by the manufacturer is how to deal with stochastic demand and ever-changing customer needs and requirements. Till recently, the three major goals guiding the manufacturing industry have been low cost, high quality and rapid responsiveness (Koren, 2013). These modern challenges have paved the way for the new manufacturing paradigm known as a Reconfigurable Manufacturing System (RMS). An RMS is defined as a manufacturing system capable of rapid changes in structure, as well as in hardware and software components, in order to quickly adjust to the dynamic demands of the 
manufacturing system (Koren et al., 1999). The concept of RMS is similar to the concepts of "Modular Manufacturing" given by Tsukune et al. (1993); "component based manufacturing systems" proposed by Weston (1999), Chirn and McFarlane (2000), Harrison, West, Weston, and Monfared (2001); "modular product system" (Rogers \& Bottaci, 1997); and "modular flexible manufacturing" (Kaula, 1998). The core characteristics of RMSs are modularity, integrability, convertibility, diagnosability, and customization (Mehrabi, Ulsoy, \& Koren, 2000). The design, implementation and operation of any RMS revolve around part families. The effectiveness of any RMS can be best judged by the number of part families which can be produced within this system after suitable reconfiguration of the system. According to Shabaka and ElMaraghy (2004), the reconfiguration process of the system can be classified into physical reconfiguration and logical reconfiguration. Examples of physical reconfigurations include layout reconfiguration, adding or removing machines, tools or components, and material handling system reconfiguration. Meanwhile, examples of logical reconfiguration include re-programming of machines, re-planning, re-scheduling, rerouting, and increasing or decreasing shifts or the number of workers.

The term "part family" or "product group" has been defined in British Standard BS 5191 as 'a number of products with one or more common characteristics, which it is convenient to combine for planning and control purposes'. Grouping of products can be considered as a requirement for RMS design in order to facilitate the production of variants of products, material purchase and production management (Abdi \& Labib, 2004; Zhang, Xu, Yu, \& Jiao, 2012). Designing a manufacturing system around a part family simply enhances the chances of customized flexibility within a system capable of producing all parts belonging to a particular part family (Dou, Dai, \& Meng, 2009; Koren et al., 1999). In a nutshell, it can be said that part families are essential aspects to RMS design and operations (Goyal, Jain, \& Jain, 2012). Product or part family formation is sometimes governed by product-process simultaneous reconfiguration (Abdi, 2012), which may further reduce capital cost. Though the definition of the RMS by Koren et al. (1999) was confined to a single part family, later, in contrast, Zhao, Wang, and Luo (2000) described an RMS as a manufacturing system in which a variety of products required by customers can be classified into families, each of which is a set of similar products, corresponding to one configuration of the RMS. The most widely used approaches for grouping products into part families are those developed by Askin, Selim, and Vakharia (1997) and Suresh, Slomp, and Kaparthi (1995). These approaches were based on cell formation in which the machine and parts were already identified. The technique developed by Ratchev (1999) employed a fuzzy clustering approach for cell formation which was aimed at selecting an optimum shop floor configuration. Heragu and Gupta (1994) and Kim (1998) used mathematical programming approaches to optimize system configuration based on a part mix for formation of part families. Several researches used quadratic programming for cell formation (Abdi \& Labib, 2004; Abdul-Hamid, Kochhar, \& Khan, 1999; Chang \& Chen, 1996). Abdi and Labib (2004) proposed an AHP approach for the formation of part families for an RMS. Detailed work was also done by Rakesh, Jain, and Mehta (2010) on the formation of part families in an RMS based on a hierarchical clustering approach.

The process of the design and subsequent operation of an RMS starts with the classification of products into part families. Subsequently, the manufacturer has to decide a suitable configuration which may be initially adopted for production of parts belonging to a part family if an entirely new product flow line facility is to be set up. However, in a realistic case, there may exist some initial flow line configurations which 
were already in operation to produce jobs as per the production requirements. In order to produce jobs for subsequent part families, these initial product flow lines may be reconfigured to suit the requirements of the future product families. The basic aim of the reconfiguration strategy is to carry out the process in an optimized way. This reconfiguration may be in the form of adding or removing machines, re-adjustment of machines, adding new machines or reconfiguring some machines for capacity or operational requirements. For any given initial product flow line, there may be several alternatives which can be adopted to reconfigure an existing line into a new product flow line for a desired part family. Thus, it is necessary that the selection of alternatives should be based on some criterion which must take into account factors associated with the changeover of this initial configuration to a new configuration. The literature reviewed on the topic revealed that most of the work on RMS takes into consideration a single part family and performance indicators of the service level have not been taken up in detail. Motivated by these gaps, the present study is focussed on addressing the issue of the service level for part families which may be taken as a performance measure indicator for RMS. The proposed methodology is explained by using an example, the details of which are summarized in the following sections.

\section{Reconfigurable Product Flow Line}

A simple product flow line is basically an arrangement of some station or stages on which some desired operations are carried out. These stations or stages are basically work centers comprising a number of machine(s). On the other hand, a reconfigurable product flow line (RPFL) can be defined as a production or manufacturing facility composed of reconfigurable machines, the configuration of which can be changed as required. The reconfiguration may be carried out either by adding or removing machine(s) from the product line, re-adjusting existing machines on various stages or stations, or by reconfiguring some machines to suit the new requirements. A RPFL can be reconfigured to suit the product requirement as and when needed. Jobs move from one stage to subsequent stages as per the required operation sequence and finally a finished product may be obtained after it passes the last stage on the product line. A schematic diagram of a product flow line is shown in Figure 1

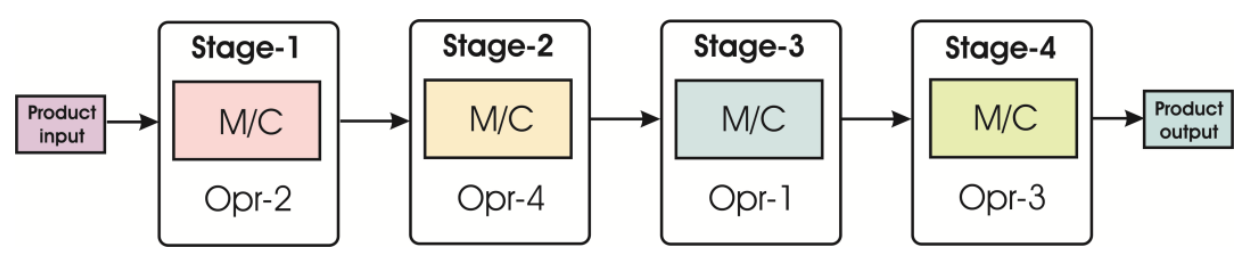

Figure 1. Schematic block diagram for a product flow line.

\section{New Index for Performance}

The main focus of modeling any RMS is based on the optimization of certain variables to carry out the reconfiguration process. Most of the researches on RMS take into account the objective of reducing the cost and reconfiguration effort required for this change in configuration. These optimization problems are based on linear programming models, neural networks, nature-inspired algorithms and many other operation researchbased techniques. The literature reviewed revealed that most of the reconfiguration 
problems are based on RMSs involving a single part family. However, (Zhao et al., 2000) a framework for a stochastic model of an RMS which involves measuring the performance based on the service level. In another work, Goyal et al. (2012) developed a reconfigurability index for reconfigurable machine tools based on set theory. In summary, it can be said that reconfigurable manufacturing systems offer several feasible alternative product flow line configurations for producing a product part family over some period of demand, and when the product family changes a corresponding change in product line configuration is required. Therefore, the problem of calculating a cumulative effort in terms of some index is required when an initial product flow line configuration is changed into other configurations required to produce multiple part families. In the present investigation, a novel methodology is suggested to develop a service level index for part families for RMS. The index of service level is based on the cumulative effort required to reconfigure an existing flow line to a new configuration as desired to produce jobs belonging to an entirely different family of products. The index proposed takes into consideration the various efforts which are involved, in adding or removing any machine from the product flow line, rearranging some machines at various stages of the line based on the operation precedence required by the product family, and reconfiguring the machines themselves to take advantage of their multiple operational capability and capacity.

\section{PROBLEM FORMULATION}

The reconfigurable product flow line allows quick changes in its configuration in response to changes in the product mix as classified by distinct part families. Here, it is important to evaluate the degree of reconfiguration effort required to handle multiple part families through the process of the reconfiguration of an existing flow line. The authors propose a new performance measure index for flow line reconfiguration based on the efforts required to carry out this change. The proposed index gives an insight into the effort required to change an existing product line configuration to a new configuration required for multiple part families. For modeling the problem, the following assumptions and notations are used:

\section{Notations}

$N$ : Number of stages on the product flow line.

$L:$ Number of part families considered.

$M_{i}:$ Reconfigurable Machine, where $i=1,2,3,4 \ldots . . N$.

$C_{\text {initial }}$ : Initial product flow line configuration.

$\varphi_{i}$ : Number of feasible options by which initial configuration $C_{\text {initial }}$ can be converted into desired configuration for a part family. where, $i=1,2,3, \ldots \ldots$.

$\alpha_{i j}$ : Reconfiguration Effort Index (RcEI) when $i^{\text {th }}$ machine is reconfigured into $j^{\text {th }}$ machine.

$\beta_{i}$ : Adding Effort Index (AEI) associated with $i^{\text {th }}$ machine.

$\gamma_{i}$ : Removal Effort Index (RmEI) associated with $i^{\text {th }}$ machine.

$\eta_{i}$ : Re-adjustment Effort Index (RjEI) associated with $i^{\text {th }}$ machine. 
$M_{r g}=\left[\alpha_{i j}\right]:$ Effort Matrix for reconfiguration of machines.

$M_{\text {add }}=\left[\beta_{i}\right]$ : Effort Matrix for adding machines.

$M_{r e m}=\left[\gamma_{i}\right]$ : Effort Matrix for Removing Machines.

$M_{\text {radj }}=\left[\eta_{i}\right]:$ Effort Matrix for Re-adjustment of machines.

$\ell$ : Number of machines added on the flow line for new configuration while changing initial configuration $C_{\text {initial }}$, where $i=1,2,3,4 \ldots \ldots . N$.

$m$ : Number of machines removed on the flow line for new configuration while changing initial configuration $C_{\text {initial }}$, where $i=1,2,3,4 \ldots \ldots . .$.

$n$ : Number of machines re-adjusted on the flow line for new configuration while changing initial configuration $C_{\text {initial }}$, where $i=1,2,3,4 \ldots \ldots . N$.

$p$ : Number of machines reconfigured on the flow line for new configuration while changing initial configuration $C_{\text {initial }}$, where $i=1,2,3,4 \ldots \ldots . N$.

$R_{\text {effort }}^{\varphi_{i}}$ : Reconfiguration effort while reconfiguring initial configuration $C_{\text {initial }}$ to new configuration using $\varphi_{\mathrm{i}}$ alternative.

$\psi_{i}$ : Service Level for $i^{\text {th }}$ part family

\section{Assumptions}

1. The various products to be manufactured are classifiable into distinct part families, $\mathrm{PF}_{\mathrm{i}}$.

2. The initial configuration of the product flow line is composed of at least 2 stages with a single reconfigurable machine $\left(M_{i}\right)$ at each stage.

3. Each machine can be reconfigured into any other type of machine as required.

4. The Reconfiguration Effort Index is the same either when the $i^{\text {th }}$ machine is reconfigured into the $j^{\text {th }}$ machine or when the $j^{\text {th }}$ machine is reconfigured into the $i^{\text {th }}$ machine, i.e. with the same effort index values when $M_{1}$ is reconfigured to $M_{2}$ and vice versa.

5. A machine can be added, removed, reconfigured or re-adjusted while modifying the flow line from any initial configuration to the desired configuration required for a part family, i.e., no machine can be reconfigured and re-adjusted simultaneously.

6. The reconfiguration effort is considered to be the highest, followed by addition effort, removal effort and re-adjustment effort. i.e. $\alpha_{i j} \geq \beta_{i} \geq \gamma_{i} \geq \eta_{i}$.

7. The various effort indices are independent of the product flow line stages.

8. The time required for changing from one configuration to another is not considered.

\section{DEVELOPMENT OF PERFORMANCE INDEX}

For the development of a performance index based on the service level of part families in a multi-part family RMS, the following four different types of effort are considered. These efforts are required to change an initial flow line configuration to a new configuration capable of handling a new part family.

Addition Effort: This effort is required to add a new machine at any stage of the product flow line. This effort is measured as an index denoted by $\beta_{i}$ which may be termed as the "Adding Effort Index (AEI)". For example, if the adding effort of 
machine $M_{1}$ is 0.4 and for machine $M_{2}$ is 0.2 , this means that more effort is required to add machine $M_{1}$ to the flow line than $M_{2}$. The various adding efforts associated with various machines are presented in a matrix denoted by $M_{\text {add }}=\left[\beta_{i}\right]$.

Removal Effort: This effort is required to remove any machine from an initial flow line configuration. The measurement index associated with this effort is denoted by $\gamma_{i}$. This effort may be termed as the "Removal Effort Index (RmEI)". As an example, the effort required to remove machine $M_{3}\left(\gamma_{3}=0.4\right)$ is more than the effort required to remove machine $M_{4}\left(\gamma_{3}=0.4\right)$. The removal effort indices associated with various machines are denoted by matrix $M_{r e m}=\left[\gamma_{i}\right]$.

Re-adjustment Effort: This is the effort related to the readjustment of machines at various stages of the flow line, if required. This may be necessary to fulfil the operation precedences of the jobs. For illustration, take any initial flow line configuration, say stage 1 comprises $M_{4}$ for a turning operation; stage 2 comprises $M_{2}$ for a drilling operation, and $M_{2}$ is installed at stage 5 for a reaming operation. Now, if a new configuration is required for a part family on which the sequence of operations is instead milling, turning and boring at stages 1,2 and 3 respectively, this implies that now machine $M_{4}$ is to be readjusted for stage 2 . The effort required for this readjustment is termed as the Re-adjustment Effort Index (RjEI). This readjustment is important to reduce the transportation time and back-tracking and to ensure the smooth flow of jobs on the flow line. This effort is denoted by $\eta_{i}$ and a complete re-adjustment matrix is presented by $M_{r a d j}=\left[\eta_{i}\right]$.

Machine Reconfiguration Effort: One of the distinguishing characteristics of RMSs are reconfigurable machine tools (RMTs). These RMT are modular machines having customized operational capability and capacity. The basic structure of these machines can be altered to vary their capacity and operational capabilities. Reconfigurable machine tools are developed as modular machines comprising different modules (Koren et al., 1999; Landers, 2000; Moon \& Kota, 2002). In the present paper, the term "Machine" is synonymous with RMT. The Machine Reconfiguration Effort (ReEI) is defined as the effort required to change the operational capability of these machines. The machine reconfiguration index is presented by $\alpha_{i j}$. For illustration, $\alpha_{23}$ presents the effort required to change the operational capability of machine $M_{2}$ to machine $M_{3}$. The complete reconfiguration effort matrix is shown by $M_{r g}=\left[\alpha_{i j}\right]$.

The various effort indices defined above can be calculated by taking factors such as cost, number of modules added/removed/adjusted for converting an RMT, space constraints etc. Recently, work has been done by Goyal et al. (2012) to calculate the reconfigurability index of reconfigurable machines. However, no literature has been found that suggests any model or expressions to calculate other indices associated with removal, addition or re-adjustment of machines when carrying out a flow line reconfiguration. In the present work, the various indices are assumed randomly in order to calculate the total reconfiguration effort required to change an existing initial configuration $C_{\text {initial }}$ to some new configuration on which jobs belonging to a part family can be processed. In order to realize this reconfiguration process, say, $\ell$ number of new machines are required to be added, $m$ number of machines are to be removed from the initial product line, $n$ number of machines needs to be readjusted and $p$ number of 
machines are to be reconfigured. Thus, the effort involved in this reconfiguration can be calculated as

$$
R_{\text {effort }}^{i}=\sum_{i=1}^{\ell} \beta_{i}+\sum_{j=1}^{m} \gamma_{j}+\sum_{k=1}^{n} \eta_{k}+\sum_{z=1}^{p} \alpha_{z}
$$

For the $i^{\text {th }}$ part family, the service level $\psi_{i}$ can be calculated as

$$
\psi_{i}=\frac{\phi_{i}}{\sum_{j=1} R_{\text {effort }}^{j}}
$$

The methodology proposed above is illustrated with the help of the following example.

\section{EXAMPLE}

Consider an RMS, to be configured for 3 part families ( $L=3)$ with machines $M_{1}, M_{2}, M_{3}$ $\& M_{4}$. The various effort matrices are

$$
\begin{gathered}
M_{\text {add }}=\left[\begin{array}{llll}
M_{1} & M_{2} & M_{3} & M_{4} \\
0.4 & 0.2 & 0.4 & 0.3
\end{array}\right] \quad M_{r e m}=\left[\begin{array}{llll}
M_{1} & M_{2} & M_{3} & M_{4} \\
0.3 & 0.2 & 0.4 & 0.3
\end{array}\right] \\
M_{r a d j}=\left[\begin{array}{llll}
M_{1} & M_{2} & M_{3} & M_{4} \\
0.2 & 0.1 & 0.3 & 0.2
\end{array}\right] \quad M_{r g}=\left[\begin{array}{ccccc}
\text { From } / T o & M_{1} & M_{2} & M_{3} & M_{4} \\
M_{1} & - & 0.7 & 0.8 & 0.6 \\
M_{2} & - & - & 0.9 & 0.7 \\
M_{3} & - & - & - & 0.8 \\
M_{4} & - & - & - & -
\end{array}\right]
\end{gathered}
$$

The initial flow line configuration, $C_{\text {initial }}$ and the various new configurations required for part families 1, 2 and 3 are shown in Figure 2.

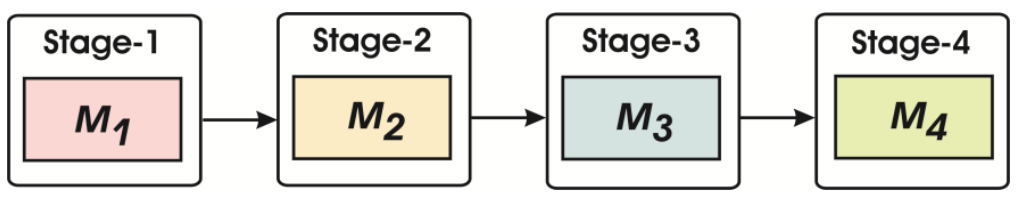

(a)

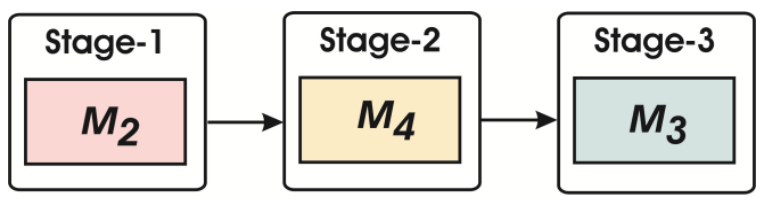

(b)

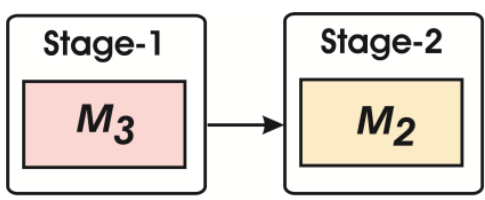

(c)

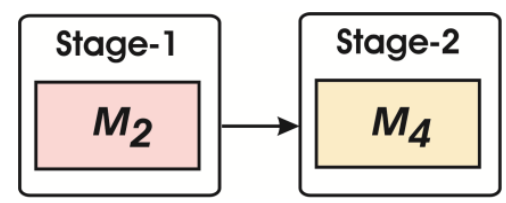

(d)

Figure 2. Flow line configurations: (a) initial configuration, $C_{\text {initial }}$, (b) for part family 1;

(c) for part family 2 ; and (d) for part family-3. 
For illustration, consider part family 1: the initial configuration $C_{\text {initial }}$ can be converted into a new configuration $\varphi_{1}$ by removing machine $M_{1}$ from stage 1 and readjusting machines $M_{2}, M_{3}, M_{4}$ to stages 1,2 and 3 respectively. The effort for this reconfiguration of the product flow line $R_{\text {effort }}^{\varphi_{1}}$ is calculated using Eq. as

$$
\begin{aligned}
& =\sum_{j=1} \gamma_{j}+\sum_{k=2,3,4} \eta_{k} \\
& =(0.3)+(0.1=0.3=0.2)=0.9
\end{aligned}
$$

Similarly, the efforts required for other configurations $\varphi_{2}, \varphi_{3}, \varphi_{4}, \varphi_{5}, \varphi_{6}$ and $\varphi_{7}$ can be calculated. Finally, the service level for part family 1 is calculated as below using Eq. (2)

$$
\psi_{i}=\frac{7}{(0.9+1.7+1.0+1.3+2.6+1.5+1.9)}
$$

Possible alternatives which can be adopted to reconfigure the initial flow line configuration, $C_{\text {initial }}$ to the configuration required for the three part families considered,

\begin{tabular}{|c|c|c|c|c|c|c|c|}
\hline & & Add & Remove & Re-adjust & $\begin{array}{c}\text { Reconfiguration } \\
\text { of RMTs }\end{array}$ & $R_{\text {effort }}^{i}$ & $\psi_{i}$ \\
\hline \multirow{7}{*}{ 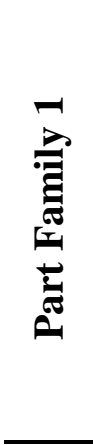 } & $\varphi_{1}$ & - & $M_{1}$ & $M_{2}, M_{3}, M_{4}$ & - & 0.9 & \multirow{7}{*}{0.64} \\
\hline & $\varphi_{2}$ & - & $M_{4}$ & - & $M_{1}$ to $M_{2}, M_{2}$ to $M_{4}$ & 1.7 & \\
\hline & $\varphi_{3}$ & - & $M_{4}$ & $M_{2}$ & $M_{1}$ to $M_{4}$ & 1.0 & \\
\hline & $\varphi_{4}$ & - & $M_{2}$ & $M_{3}, M_{4}$ & $M_{1}$ to $M_{2}$ & 1.3 & \\
\hline & $\varphi_{5}$ & - & $M_{3}$ & - & $M_{1}$ to $M_{2}, M_{2}$ to $M_{4}, M_{4}$ to $M_{3}$ & 2.6 & \\
\hline & $\varphi_{6}$ & - & $M_{3}$ & $M_{2}, M_{4}$ & $M_{1}$ to $M_{3}$ & 1.5 & \\
\hline & $\varphi_{7}$ & - & $M_{1}$ & - & $M_{3}$ to $M_{4}, M_{4}$ to $M_{3}$ & 1.9 & \\
\hline \multirow{4}{*}{ N } & $\varphi_{1}$ & - & $M_{3}, M_{4}$ & & $M_{1}$ to $M_{3}$ & 1.4 & \multirow{4}{*}{0.67} \\
\hline & $\varphi_{2}$ & - & $M_{1}, M_{4}$ & $M_{2}, M_{3}$ & - & 1.0 & \\
\hline & $\varphi_{3}$ & - & $M_{1}, M_{2}$ & $M_{3}$ & $M_{4}$ to $M_{2}$ & 1.5 & \\
\hline & $\varphi_{4}$ & - & $M_{2}, M_{3}$ & - & $M_{1}$ to $M_{3}, M_{4}$ to $M_{2}$ & 2.1 & \\
\hline \multirow{4}{*}{ 赵 } & $\varphi_{1}$ & - & $M_{1}, M_{3}$ & $M_{2}, M_{4}$ & - & 1.0 & \multirow{4}{*}{0.59} \\
\hline & $\varphi_{2}$ & - & $M_{3}, M_{4}$ & - & $M_{1}$ to $M_{2}, M_{2}$ to $M_{4}$ & 2.1 & \\
\hline & $\varphi_{3}$ & - & $M_{1}, M_{2}$ & $M_{4}$ & $M_{3}$ to $M_{2}$ & 1.6 & \\
\hline & $\varphi_{4}$ & - & $M_{2}, M_{4}$ & - & $M_{1}$ to $M_{2}, M_{3}$ to $M_{4}$ & 2.0 & \\
\hline
\end{tabular}
along with $R_{\text {effort }}^{i}$ and $\psi_{i}$, are presented in Table 1.

Table 1. Results for service level values $\psi_{i}$ obtained for the RMS considered. 


\section{RESULTS AND DISCUSSION}

The developed index of service level, $\psi_{i}$, gives a fairly reasonable idea of the effort needed to reconfigure any initial flow line configuration $C_{\text {initial }}$ to a new configuration required for any part family. The developed index of service level may be taken as a function of two parameters, one associated with the reconfiguration effort value $R_{\text {effort }}^{i}$ and the other related to a number of possible alternatives $\varphi_{i}$ by which this change in the existing configuration can be achieved. The relationship between $\psi_{i}, R_{\text {effort }}^{i}$ and $\varphi_{i}$ is that $\psi_{i}$ is directly proportional to $\varphi_{i}$, but inversely proportional to $R_{\text {effort }}^{i}$. This proportionality is quite justifiable, as a higher reconfiguration effort means a low service level and the higher the number of alternatives by which this reconfiguration can be achieved, the higher will be the service level. The results obtained for the example considered clearly demonstrate the above relationships. In the example, based on the initial configuration the highest service level is obtained for part family $2\left(\psi_{2}=0.67\right)$ and the lowest service level of 0.59 is obtained for part family $3\left(\psi_{3}\right)$. A simple interpretation of this is that changing the initial configuration to the new configuration is easier for part family 2 than for part family 3 . In that case, if the system is dealing with a single part family, then for part family 1 , the initial configuration $C_{\text {initial }}$ must be reconfigured to configuration $\varphi_{1}$ as it requires less effort (0.9) than any of the other configurations. Similarly, for part families 2 and 3 , the optimum reconfigurations from the initial configuration $C_{\text {initial }}$ are $\varphi_{2}$ and $\varphi_{1}$ with effort values of 1.0 each. However, the present work is just a preliminary study for establishing the service level index of part families as a performance indicator of reconfigurable manufacturing systems. In the literature, almost no study was found that takes into account this kind of measure. The physical relevance and the implications of this study are that the manufacturer can get an insight into how the present configuration of the flow line can best be changed to get the maximum benefit. Further, this also enables the manufacturer to assess the relevant importance of each part family, and also, if there are multiple existing flow line configurations, which configuration can be changed to which new configuration in order to ensure the maximum performance of the system.

\section{CONCLUSIONS}

The present work proposed a novel methodology for calculating the service levels of various part families under various product flow line configurations. The developed index of service level can be taken as one of the performance indicators of RMS. The proposed methodology can be used for selecting any initial flow line configuration which may be reconfigured in future to accommodate multiple part families. Optimum selection of an initial flow line configuration is important, as it has serious implications for the cost of reconfiguring it for different part families required in the near future. Since this index was developed based on certain assumptions, a better index may also be devised in future, incorporating many other parameters which are assumed in this study. A methodology might be proposed to calculate indices like the addition effort, removal effort and re-adjustment effort, all of which are arbitrarily assumed in the present work. Furthermore, the study might be replicated to include optimization as well. 


\section{ACKNOWLEDGEMENTS}

The authors are extremely grateful to the referee(s) for their valuable suggestions which helped in improving the quality and readability of the paper.

\section{REFERENCES}

Abdi, M. R. (2012). Product family formation and selection for reconfigurability using analytical network process. International Journal of Production Research, 50(17), 4908-4921.

Abdi, M. R., \& Labib, A. W. (2004). Grouping and selecting products: The design key of reconfigurable manufacturing systems (rmss). International Journal of Production Research, 42(3), 521-546.

Abdul-Hamid, Y. T., Kochhar, A. K., \& Khan, M. K. (1999). An analytic hierarchy process approach to the choice of manufacturing plant layout. Proceedings of the Institution of Mechanical Engineers, Part B: Journal of Engineering Manufacture, 213(4), 397-406.

Askin, R. G., Selim, H. M., \& Vakharia, A. J. (1997). A methodology for designing flexible cellular manufacturing systems. IIE Transactions, 29(7), 599-610.

Chang, C. H., \& Chen, Y. (1996). Autonomous intelligent agent and its potential applications. Computers \& Industrial Engineering, 31(1-2), 409-412.

Chirn, J. L., \& McFarlane, D. C. (2000, 2000). A holonic component-based approach to reconfigurable manufacturing control architecture. Paper presented at the Database and Expert Systems Applications, 2000. Proceedings. 11th International Workshop on.

Dou, J. P., Dai, X. Z., \& Meng, Z. D. (2009). Optimisation for multi-part flow-line configuration of reconfigurable manufacturing system using ga. International Journal of Production Research, 48(14), 4071-4100.

Goyal, K. K., Jain, P. K., \& Jain, M. (2012). A comprehensive approach to operation sequence similarity based part family formation in the reconfigurable manufacturing system. International Journal of Production Research, 51(6), 1762-1776.

Harrison, R., West, A. A., Weston, R. H., \& Monfared, R. P. (2001). Distributed engineering of manufacturing machines. Proceedings of the Institution of Mechanical Engineers, Part B: Journal of Engineering Manufacture, 215(2), 217-231.

Heragu, S. S., \& Gupta, Y. P. (1994). A heuristic for designing cellular manufacturing facilities. International Journal of Production Research, 32(1), 125-140.

Kaula, R. (1998). A modular approach toward flexible manufacturing. Integrated Manufacturing Systems, 9(2), 77 - 86.

Kim, I. (1998). Managing variances in manufacturing system design. European Journal of Operational Research, 109(3), 571-586.

Koren, Y. (2013). The rapid responsiveness of rms. International Journal of Production Research, 51(23-24), 6817-6827.

Koren, Y., Heisel, U., Jovane, F., Moriwaki, T., Pritschow, G., Ulsoy, G., \& Van Brussel, H. (1999). Reconfigurable manufacturing systems. CIRP Annals Manufacturing Technology, 48(2), 527-540. 
Landers, R. G. (2000). A new paradigm in machine tools: Reconfigurable machine tools. Paper presented at the Japan-USA Symposium on Flexible Automation, Ann Arbor, MI.

Mehrabi, M. G., Ulsoy, A. G., \& Koren, Y. (2000). Reconfigurable manufacturing systems: Key to future manufacturing. Journal of Intelligent Manufacturing, 11(4), 403-419.

Moon, Y. M., \& Kota, S. (2002). Design of reconfigurable machine tools. Journal of Manufacturing Science and Engineering, 124(2), 480-483.

Rakesh, K., Jain, P. K., \& Mehta, N. K. (2010). A framework for simultaneous recognition of part families and operation groups for driving a reconfigurable manufacturing system. Advances in Production Engineering and Management, 5, 45-58.

Ratchev, S. M. (1999). Dynamic formation of extended manufacturing cells for increased system responsiveness. Paper presented at the Proceedings of 9th International Flexible Automation and Intelligent Manufacturing (FAIM) Conference.

Rogers, G. G., \& Bottaci, L. (1997). Modular production systems: A new manufacturing paradigm. Journal of Intelligent Manufacturing, 8(2), 147-156.

Shabaka, A. I., \& ElMaraghy, H. A. (2004). Structural mapping between operation clusters and machine configuration for rms. Paper presented at the Proceedings of the International Workshop on Advanced Manufacturing Technologies (AMT 2004), Ontario, Canada.

Suresh, N. C., Slomp, J., \& Kaparthi, S. (1995). The capacitated cell formation problem: A new hierarchical methodology. International Journal of Production Research, 33(6), 1761-1784.

Tsukune, H., Tsukamoto, M., Matsushita, T., Tomita, F., Okada, K., Ogasawara, T.et al.Yuba, T. (1993). Modular manufacturing. Journal of Intelligent Manufacturing, 4(2), 163-181.

Weston, R. H. (1999). Model-driven, component-based approach to reconfiguring manufacturing software systems. International Journal of Operations \& Production Management, 19(8), 834-855.

Zhang, L. L., Xu, Q., Yu, Y., \& Jiao, R. J. (2012). Domain-based production configuration with constraint satisfaction. International Journal of Production Research, 50(24), 7149-7166.

Zhao, X., Wang, J., \& Luo, Z. (2000). A stochastic model of a reconfigurable manufacturing system part 1: A framework. International Journal of Production Research, 38(10), 2273-2285. 